\title{
Toxicomania e a cadeia circular das Interações Familiares A terapia familiar como teoria para a
reconstrução da cidadania
}

\section{Lacete Maria Lehnen Mestre em Psicologia UnB/DF.}

O presente trabalho, sustentado no referencial sistêmico, traz elementos importantes para a descrição de um ciclo repetitivo nas interações de famílias como um membro toxicômano que se retroalimenta, sendo composto de vários momentos que se sucedem, se repetem e, aos poucos, se cronificam no interior da familia. Para discorrer sobre este ciclo vou partir dos resultados de minha dissertação de Mestrado realizado em uma Instituição de Saúde Pública em Brasília. Utilizarei a fim de ilustrar o trabalho a fala dos sujeitos PI que os identifico como Caroline, Laura, Cláudio e Luciano, resgato unidades do discurso de suas familias que se tornaram para mim familiares num período de aproximadamente dois anos, e o são até hoje habitantes de meu pensamento e provocadores de reflexões e questionamentos que, ainda, permanecem e que me fazem continuar tentando compreender a complexidade do fenômeno das toxicomanias.

O jogo relacional adotado nas famílias de toxicômanos mostra que as interações são estabelecidas através de um caráter circular e repetitivo, a fim de impedir qualquer forma de mudanças que possam ameaçar o sistema.
0 texto discute as relaçōes familiares no âmbito de familias de toxicomanos, enfatizando aspectos cíclicos e repetitivos que tendem a impedir mudanças no padrão das interações. A autora questiona, finalmente, se é possivel que algumas alternativas de intervençăo possam quebrar aquela cadeia de interaçoes.

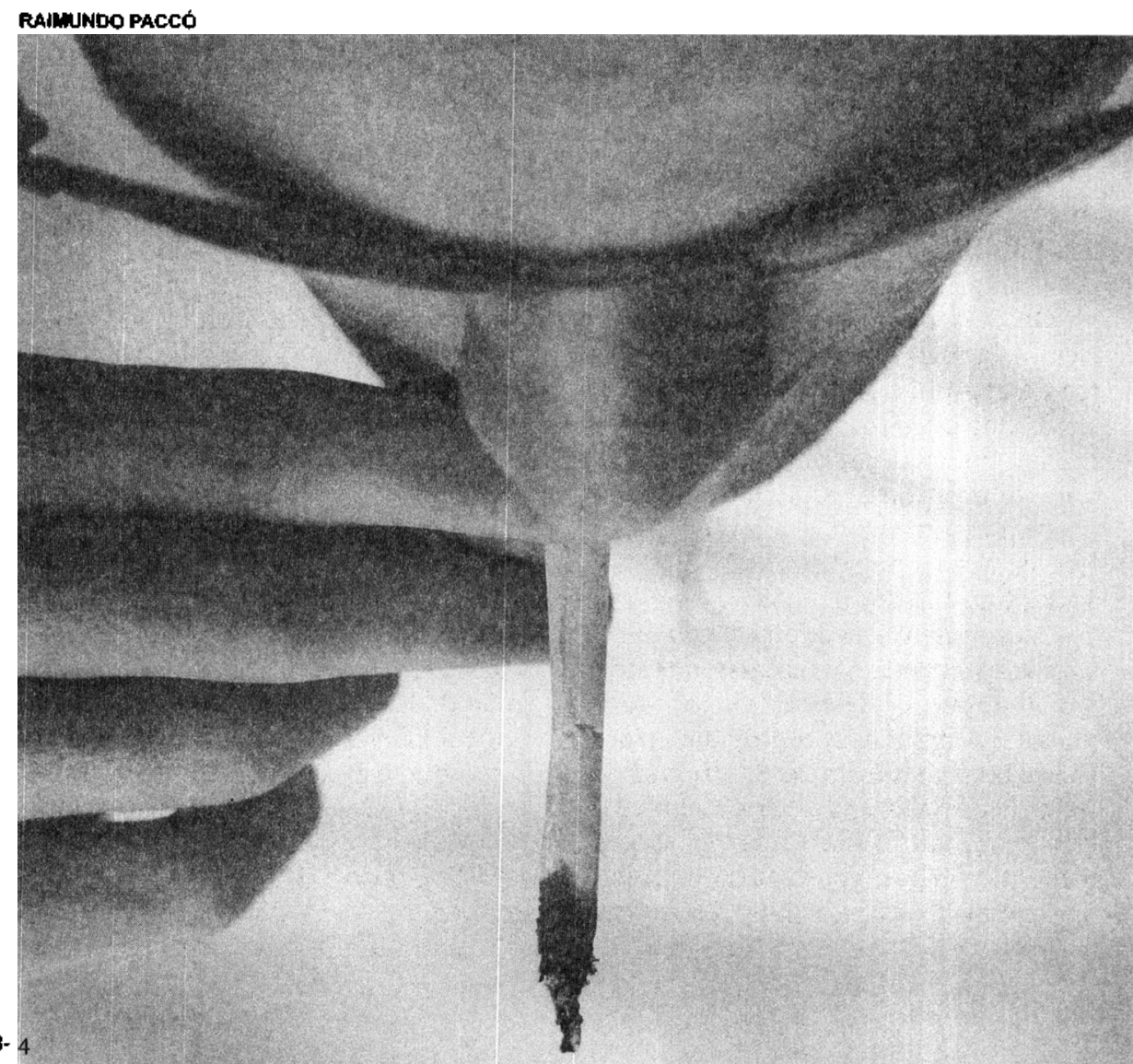


A cadeia circular das interações se manifesta primordialmente na dinâmica das relações com o padrão đisfuncional, ou seja, NA POSIÇĀO TRIANGULADA, expressas na aliança entre o casal e o paciente identificado.

No movimento de entrada e saída de casa, o toxicómano incorpora vida ao processo das interações no interior da família, evidenciando que a cadeia circular das relaçōes garante por um momento a manifestação do sintoma e por outros momentos o seu desaparecimento, a fim de assegurar a própria sobrevivência do sistema.

Nos casos analisados, observou-se que o sintoma revela-se numa ocasião de tensão familiar, onde o toxicômano reivindica sua autonomia, e o triângulo de sustentação é ameaçado. Nesta circunstância, o filho portador do sintoma parece retirar-se a fim de resgatar suas capacidades e mostrar para a família que pode separar-se. Entretanto, em cada afastamento, o filho retoma seu dilema entre permanecer e desempenhar o papel designado, ou partir e desmembrar o sistema, da mesma forma que reativa na família o temor frente às possibilidades de rompimento.

Assim, na perspectiva do movimento de saída, a tentativa de ruptura do toxicômano com sua familia constituise numa ameaça que causa pânico ao sistema. Se por um lado suas saidas depois de um conflito familiar representam a possibilidade de criar vínculos externos atendendo às suas necessidades como adolescentes em crescimento, traduzem-se para a família como uma viabilidade a caminho de mudanças que precisam ser evitadas a qualquer preco.

Observou-se que neste momento do ciclo a família se reveste de sentimentos de abandono, e, para o filho, tratase de um momento de busca de autonomia, onde o sintoma revela-se como uma solução para romper a interação triádica disfuncional que o filho estabelece com seus pais (Sternschuss et alli, 1982; Stanton et alli, 1985).

Esta dimensão pode muito bem ser transcrita através do discurso das famílias analisadas, onde se faz Caroline a porta-voz deste momento, quando as suas saídas ao encontro da droga revela-se como uma tentativa de afastar-se das relações familiares carregadas de tensões: "Sinto uma tristeza profunda que me faz sair de casa, e com a droga encontro alívio para esta angústia".
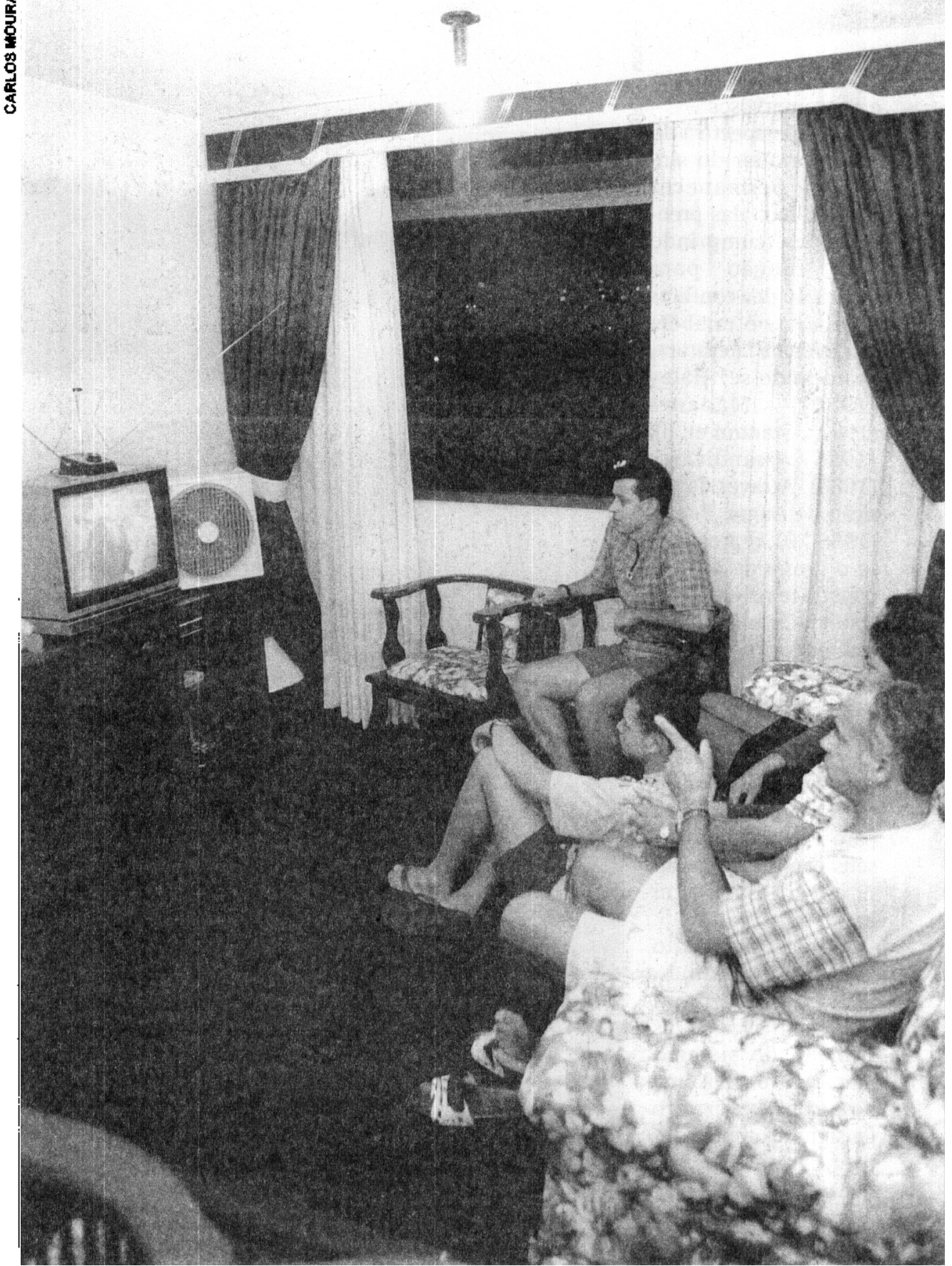

Em contrapartida, ficou claro que também a família utiliza-se de uma ma. nobra interacional a fim de estimular a saida do filho. Esta exclusão é resultado de um processo de relações recíprocas tanto da família quanto do adolescente - necessária para manter-se o jogo das interações repetitivas. Exemplifica-se esta dinâmica através do depoimento da mãe de Cláudio, quando reconhece que joga o filho para fora de casa: "Às vezes acho que brigo muito. Ele deve pensar: - Ficar ouvindo reclamação o dia inteiro? É melhor sair!".

O período em que o toxicômano permanece fora constitui-se no momento de maior apreensão familiar porque pode representar a revivescência dos conflitos conjugais que ameaçam a estabilidade do sistema. A possibilidade de rompimento que se instaura é sentida como viabilidade de dissolução do ciclo da tríade disfuncional, instante em que o casal, preocupado com a saída do fitho, mobiliza-se num processo de espera de seu retorno para recuperá-to.

Assim, o sintoma cumpre sua função de manter encobertas todas as dificuldades familiares, porque, simultaneamente, há uma inquietação de todos os membros do sistema, o que pode ser muito bem traduzido através de alguns fragmentos do discurso das famílias, como: "Ninguém dorme quando ele sai; 
- Todos se preocupam e ficam nervosos".
Esta perspectiva do filho portador do sintoma permanecer como o foco das preocupações, cumprindo uma função para ocultação dos conflitos familiares, é também discutida na Literatura, destacando-se: Haley (1980), Madanes (1982), Stanton et alli (1985), Usandivaras (1985). Através da posição de Angel, P. e S. (1988:20), representase o grupo de autores quando revelam: "A estratégia familiar basicamente gira ao redor da espera, da apreensão do retorno do toxicômano ou da sua partida. $\mathrm{O}$ drogáticto personifica este ausente-presente necessário para o casal encobrir os seus conflitos e garantir a homeóstase familiar".

Viu-se, até então, que para a família a saída do filho representa a ameaça de dissolução do sistema, mas para o toxicômano encontro com a droga significa tentar desprender-se da carga onerosa de seu papel e de trama relacional familiar que impede o seu crescimento. Entretanto, busca ilusoriamente sua autonomia no contato efêmero com o grupo externo.

As interações externas atendem, por um breve período, às necessidades do toxicômano, mas na realidade vêm a reforçar $o$ vínculo de dependência familiar, pois os membros do seu grupo passam pela mesma busca de autonomia $e$ tentativa de rompimento com suas famílias - vivenciam dinamicamente um processo semelhante. Assim, as interaçôes com a "subcultura" da droga chegam a um nível de saturação em que o proprio grupo o devolve para a famí. lia frágil e indefeso.

Nessa dimensão, o que foi uma tentativa de independização acaba por solidificar ainda mais sua dependência. A mesma estratégia interacional adotada pela familia, que joga por um momento o filho para fora, é repetida pelo grupo, que o expulsa, devolvendo o companheiro à família.

O que na verdade ocorre é a sua pseudo-individuação, noção introduzida por Stanton et alli (1985) para representar e definir o processo fracassado de rompinento do toxicômano com o sistema familiar a partir de sua interação com o grupo de pares.

Assim o sintoma, a nível das interações extrafamiliares, cumpre a função de LIMITAR O PROCESSO DE INDIVIDUAÇÃO DO FILHO, pois reforça sua dependência à família. Vislumbra-se uma solução paradoxal: na tentativa de busca de autonomia, reforça os padrões disfuncionais alimentando o caráter repetitivo das interações, mantendo o sistema estático e sem mudanças.

Para fins de uma análise mais profunda da trajetoria entre a saida do fitho de casa para encontrar a droga e o seu retorno precisando de ajuda, pode-se valer de um antigo provérbio: "Um por todos e todos por um". Ao dimensioná-lo a nível sistêmico, ele exemplifica perfeitamente $o$ processo entre a busca de autonomia do toxicómano e a resultante de reforço de sua dependência, ou seja, sua "pseudoindividuação".

Na premissa "Um por Todos", transcreve-se a posição do toxicômano frente ao sistema como o salvador, pois ao doar sua capacidade de crescimento em favor da homeóstase, mostra que renuncia a si mesmo para restabelecer a estabilidade da família. Estas exigências embutidas na tarefa do filho como PI são expressas no discurso das famílias do presente estudo, quando asseguram uma imagem de um filho necessitado que depende de sua familia, identificando 0 a nível interno como filho diferente e desqualificado: "Caroline sempre foi nervosa e doente"; - "Laura tem a natureza ruim"; - "Cláudia não muda mesmo, sempre foi capeta;" - "Luciano é um marginal".

Nessa perspectiva, a presente investigação vem ao encontro das noções desenvolvidas por Sternschuss et alli (1982), quando se referem sobre o MITO DO SACRIFÍCIO, onde o filho, como mau e diferente, cumpre uma pena sacrificando-se por toda a familia, e através deste encargo mantém oculta a disfunção familiar, porque toda a responsabilidade é delegada ao filho portador do sintoma.

Entretanto, na medida em que o fitho se expõe às interações externas, a familia une-se e solidariza-se, e os membros do sistema são unánímes em vê-lo 
como vítima do contexto social, conforme expressam em seu discurso: "Os amigos o influenciatam" (todos os casos). Segundo a famflia, o filho volta sempre doente por influência dos companheiros, obrigando-a a mobilizar-se para ajudá-lo, e todos mantêm a atençăo sobre ele.

A partir de tais consideraçōes, introduz-se o segundo ponto do provérbio. "Todos por Um", que se associa perfejtamente ao MITO DO PERDÄO (Sternschuss et alli, 1982), que objetivamente pode ser interpretado da seguinte forma: somente se o filho vem arrasado e fragilizado pode ser perdoado.

Essa posiçăo rígida da familia frente as relaçōes externas do toxicômano mostra ser uma estratégia a fim de proteger o próprio sistema. Se internamente o fitho possui uma imagem desqualificada, externamente é necessária a utilização de tal manobra de projeção de culpa aos amigos, porque desta maneira inviabilizam qualquer questionamento que possa alterar as interações familiares em seus padrões disfuncionais.

Se por um lado o toxicômano é destinado a ser "mau", porque esta posição não se constitui ameaça ao sistema, por outro lado, retornando à família "doen-

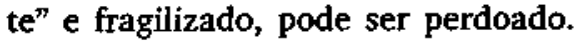

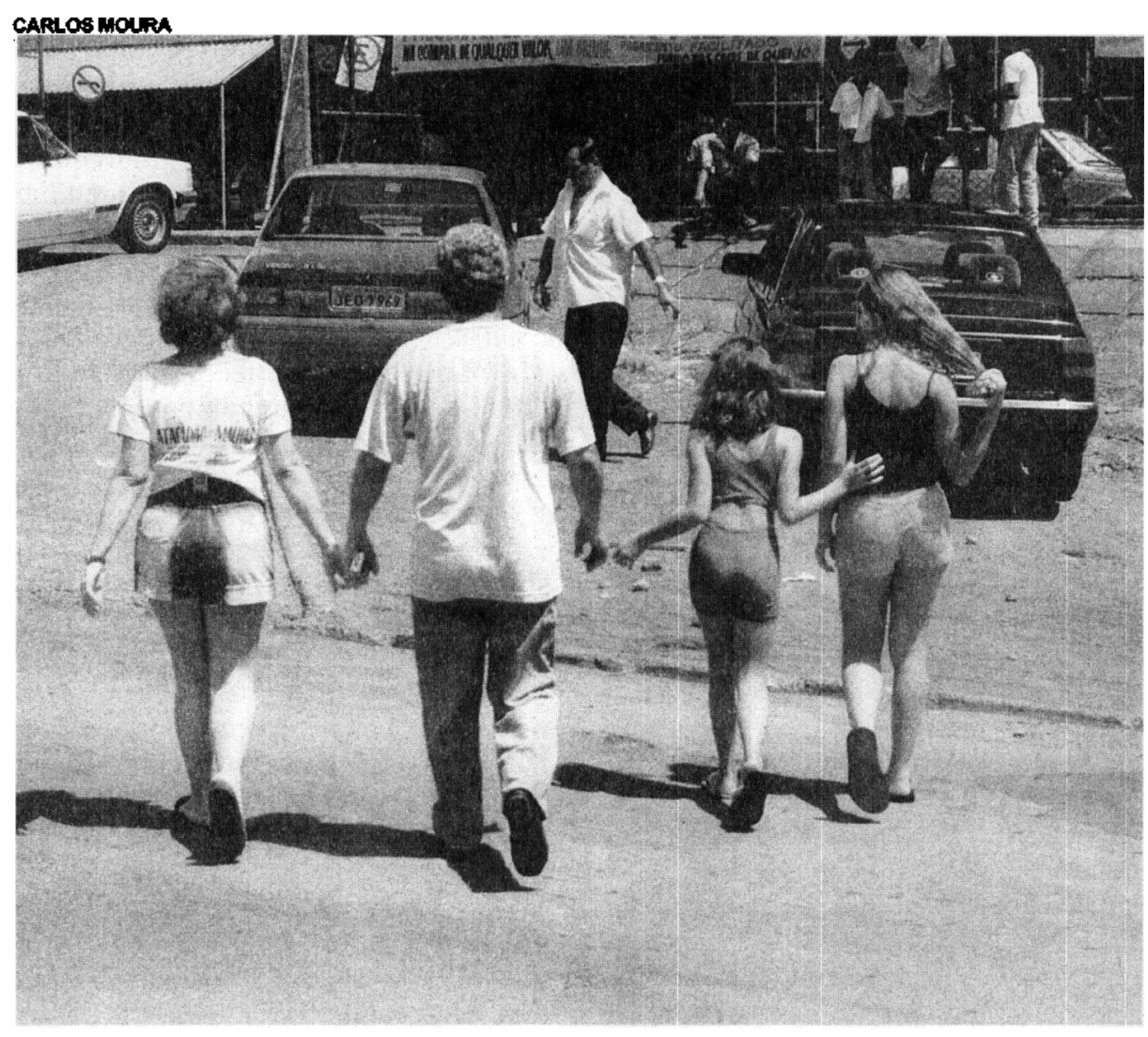

Assim, pode-se transcrever que o Mito do Sacrifício e o Mito do Perdão parecem ser o elo para assegurar o Mito da Harmonia, no qual a droga vem a ser o jeito de expiar sua culpa e receber o perdão da familia.

Diante desta análise cabe ressaltar as afirmaçöes de Stanton et alli (1985:37) quando identificam que "o ciclo da edição serve para dar aparência de movimento dramático dentro da famlia, enquanto a triade se dissolve e se restabelece outra vez. $O$ adicto participa de um padrăo homeostático de ida e volta entre o seu grupo e o seu lugar".

Seguindo esta linha de pensamento, passa-se a entender que o comportamento dependente que o toxicómano assume no momento de seu retorno à família favorece a reaproximação das relaçōes que falsamente se romperam. Se as saídas do filho podem representar a ameaça de desmembrar a família, o seu regresso - expressando o pedido de aju$\mathrm{da}$ - reflete a verdade de que um precisa do outro para o sistema sobreviver. Este extremo apego entre os membros da familia é amplamente discutido pelos estudiosos da problemática toxicômana, tais como: Sternschuss et alli (1982); Stanton et alli (1985); Usandivaras (1985); Kalina (1988); Yaria (1988).
A nivel dos casos estudados, observou-se que o toxicómano, ao retornar para casa, sucumbe frente dे necessidade de auxílio, permitindo o exercicio protetor dos pais, que nessas circunstâncias encobrem os conflitos conjugais, ou seja, o sintoma favorece a graduação destas dificuldades que ora são retraídas em favor do filho necessitado, equilibrando o subsistema conjugal.

Neste movimento de regresso para casa, constatou-se díades mais significativas do toxicômano com sua mäe. Os conflitos de separação e individuação com a própria família de origem parece, nesse instante, repetir-se com o fitho que ameaçava abandonar sua família. Retornando, O SINTOMA CUMPRE A FUNÇÃO DE NÃO DESAGREGÁ-LA, atendendo ao compromisso exigido em seu papel, em manter-se fiel ao sistema, firmando $o$ acordo implícito destas familias de que năo haverá mudanças.

A díade formada entre mãe e filho permite escalonar o "stress" conjugal. O filho salvou o casal e, conseqüentemente, o sistema (Mito do Sacrifício). Assim, tem um crédito ao regressar fragilizado precisando de ajuda (Mito do Perdão). Os pais saldam seu débito para com o filho que abdicou de si próprio para preservar a familia que ora o consagra através do investimento do exercicio parental. Neste momento, O SINTOMA CUMPRE SUA FUNÇÃO DE AGILIZAR O SUBSISTEMA PARENTAL.

Se o mérito do exercício parental é a garantia da existência conjugal, o prêmio ao toxicômano é o recebimento de cuidados especiais, expressos principalmente pela DOAÇĂO MATERNA. Observa-se que no instante da aliança entre mãe e filho dá-se o desaparecimento momentâneo do sintoma.

Este aspecto da extrema doação materna e o vínculo de dependência - no momento da recuperaçăo do filho - entre o toxicốmano e sua mãe tem sido bastante destacado na Literatura por Moujan e Mazieres (1978); Sternaschuss et alli (1982); Stanton et alli (1985); Usandivaras (1985); Kalina (1988). Através das palavras de Usandivaras (pág. 75) pode-se representar esta dinâmica: "Sempre tem um membro da família que é cúmplice do drogádicto, mais freqüentemente a mãe, sendo superprotetora e superindulgente".

Neste particular pode-se discutir tal vínculo sob a seguinte dimensão: através da dependência do filho à mãe, solidarizam-se mutuamente na preserva- 
ção da familia, parecendo repetir-se a relaçăo simbiótica da infância, evidenciando o mesmo padrăo relacional quando a díade mãe-filho se bastava, período em que o pai aparece com um papel menos fundamental.

No entanto, na ótica sistêmica em que se baseia a presente investigação, cabe o questionamento: o que se passa com relaçăo ao pai ou marido? Autores como Olivenstein (1982), Usandivaras (1985) e Kalina (1988) referem-se a este pai como uma pessoa "ausente, periférica, débil, omissa e às vezes autoritária, mas impotente face à esposa".

Entretanto, o presente estudo permite visualizar a posição do pai-marido em uma perspectiva mais abrangente defendendo-se a hipotese de que o processo que se instala não corresponde exatamente a uma ausência ou debilidade da figura masculina. $O$ que ocorre nestas familias, ou mais especificamente nestes casais, é um jogo recíproco e complementar, em que o marido também participa na medida em que permite à esposa ocupar este lugar protetor e privilegiado junto ao filho.

Assim, a aparente exclusão do pai representa, na realidade, mais uma manobra interacional de cumplicidade e de conivência entre os esposos para manter as regras do jogo instaurado. Não cabe, portanto, tecer consideraçōes no sentido de que o pai não cumpre o seu papel, mas identificar qual o papel que ele desempenha permanecendo nesta posiçăo inferior. Nessa dimensăo, o que fica claro é o quanto, neste momento, a "fraqueza" do pai vem reforçar a "fortaleza" da mãe.

Este trabalho evidenciou que, para ser possível assegurar a dinâmica estabilizadora nestas familias, necessariamente, o pai, excluindo-se indiretamente na recuperação do filho, favorece a relação simbiótica mãe e filho quando criança - ou seja, tal como o toxicômano se apresenta nesse momento. Sob uma ótica interacional, a figura paterna encontra-se AUSENTE-PRESENTE. Observa-se, pois, que de uma ma-

questionamento: "Qual seria exatamente a dinåmica que se estabelece neste jogo interacional que promove o afastamento do pai $e$ paradoxalmente the confere uma função?".

A nível desta pesquisa, pode-se dizer que, por um lado a díade mãe-filho é reconfiguradora de um quadro de interações infantis repetitivas, por outro lado, o pai credita o espaço necessário para a estagnaçăo desta relação, perpetuando a cadeia circular. A figura paterna cumpre sua função reavendo a m od a 1 i d a d e interacional com of filho da infância, alimentando o vínculo exclusivo entre mãe e toxicômano, encontrando-se simultaneamente no cenário do ciclo da tríade disfuncional.

Diante deste quadro, pode-se adicionar que na requalificação da mãe como figura materna, as dificuldades no seu papel de esposa são suprimidas, da mesma forma que o marido exclui-se de suas funçőes de esposo ajudando a manter ocultos os conflitos conjugais, auxiliando indiretamente, como figura paterna, o filho

neira ou de outra este pai cumpre uma função no contexto.

Esta dimensão de análise foi também abordada por Sudbrack - (1987) quando concluiu em sua pesquisa que a figura patema em famólias de delinqüentes ocupa uma posição que a autora identificou como "semipresente". Da mesma forma, o presente estudo constatou que, em famílias de toxicômanos, o pai mantém-se - por um momento - aparentemente excluido.

Trata-se de uma questão complexa que deve ser mais explorada em futuras pesquisas com familias de toxicômanos, sugestão esta que se baseia no seguinte doente.

Esta dimensão de que o filho portador do sintoma protege os pais, e sua sintomatologia os mantêm unidos, é destacada por um número expressivo de autores sistêmicos, cuja dinâmica, conforme atesta a Literatura, atinge também outras situações sintomáticas e não apenas a toxicomania, como a delinquiência, as doenças psicossomáticas e a esquizofrenia. Minuchin (1974), Auseoss (1978), Haley (1980), Slusky (1981), Madanes (1982), Sternschuss et alli (1982), Stanton et alli (1985) e Usandivaras (1985) são alguns representantes desta teoria. 
Fica clato, portanto, que, no processo circular das transaçóes no interior da familia, nada muda, pois no momento em que o filho é recuperado é favorecida a reaproximaçăo dos pais como casal e - sistema vai cedendo lugar às interações disfuncionais, que promovem novamente a busca do sintoma.

Este momento fica exemplificado através do presente estudo: nos casos Laura e Luciano, rivalização do toxicómano com o genitor do mesmo sexo: nos casos Caroline e Claudio, projeção de culpa ao filho portador do sintoma pelas suas dificuldades pessoais e pelos problemas familiares. Segundo Slusky (1981:140), "trata-se de uma matriz interacional presente, onde as condutas indutoras do sintoma promovem a sua manutençăo".

Assim, na trajetória do ciclo das interaçðes, o filho restabelecido passa a reivindicar sua autonomia, o dilema entre permanecer ou partir reativa-se recompondo a situação original desencadeante do sintoma; o triângulo de sustentação é novamente ameaçado e the é exigido o sacrifício pela familia, instante em que retoma o comportamento sintomático indo ao encontro da droga; e o processo ć́clico e repetitivo vem reaver 0 estilo das interações provedoras do sintoma para a preservação do sistema.

Para melhor exemplificar, tenta-se, através do gráfico, a seguir, representar a cadeia repetitiva das interações familiares - resgatando as conclusões do trabalho e, a coerência teórica sistêmica quando define o ptincípio de "globalidade", este, traz a noção de que "toda" e qualquer parte de um sistema está relacionada de tal modo com as demais partes que uma mudança numa delas provocará mudança em todas as partes e, consequientemente, no sistema total. Isto é, um sistema comporta-se não.como um simples conjunto de elementos independentes mas como um todo coeso e inseparável". Watzlawick et alli (1967:112).

A partir das conclusões do presente trabalho tenho pontuado novos questionamentos sobre a problemática - drogas, como uma necessidade emergente por parte das instituiçöes de saúde pública em implantar projetos de prevençắo, para que a população de risco à dependência e seus familiares possam resgatar o direito a cidadania:
- O sintoma "droga" que mobilizou a demanda, garantiu a família comunicar, através do sintoma específico, os próprios conflitos e expressar a necessidade de mudança?

- A busca de ajuda, através do registro do sintoma "droga", revela em última instância a capacidade da família em reorganizar-se e quebrar o ciclo das interaçöes repetitivas e disfuncionais criando uma anti-homeóstase?

- Incluindo a familia no processo terapêutico é possível criar uma anti-

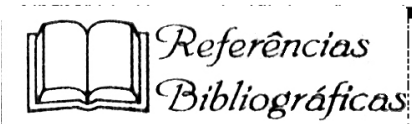

AUSLOSS, G. (1978). Aporoche Systémique et Thérapie Familiale in Marginalité Système et Familie. Vaucresson, CRIV/IES, 1979.

ANGEL, S. \& P. (1988). Drogadiccion y Familia in Revista Terapia Famillar. 18:17-23. Buenos Aires, Ediciones A.C.E.

HALEY, J. (1980). Transtomos de la Emancipación Juvenil y Terapia Familiar. Buenos Aires, Amorrortu Editores, 1985.

HALEY, J. (1980). Le Processus Therapeutique: Un Probleme d'heroine in Cahiers Critiques de Thérapia Familiale et de Pratiques de Réseaux. 6:121-135., Paris, Editions Universitaires, 1982.

KALINA, E. (1988). Drogadicçåo II. Rilo de Janeiro, Francisco Alves.

LEHNEN, L. M., (1991). A Toxicomania na Adolescêncla como um Sintoma nas Interações Familiares. Brasília, Dissertaçăo de Mestrado, Universidade de Brasilia, DF.

MADANES, C.; DUKES, J. HARBIN, H. (1980). Liens Familiaux des Heroinomanes in Cahiers Critiques de Thérapie Famlliale et de Practiques de Réseaux, 6: 87-100, 1982.

MADANES, C. (1982). Terapia Familiar Estratégica. Buenos Aires, Amorrortu Editores, 1984.

MINUCHIN, S. (1974). Famillas, Funclonamento e Tratamento. Porto Alegre, Artes Médicas, 1982.

MOUJAN, F. O. y MAZIERES, R.C. (1978). Grupo de Padres in Revista Terapia Familiar, 2:4476. Buenos Aires, Ediciones A.C.E.

OLIVENSTEIN, C. (dinigido por) (1982). A Vida do Toxicômano. Rio de Janeiro, Zahar ed., 1983.

SLUSKY, C. (1981). Processo de Producción y Pautas de Mantenimiento de Sintomas in Revista Terapia Familiar, 12;139-156. Buenos Aires, Ediciones A.C.E. 1983.

STANTON, M.D., TODD, T.C, y cols. (1985). Terapia Famlliar Del Abuso y Adicclón a las Drogas. Barcelona, Gedisa Editorial, 1988.

STERNSCHUSS, S. (1982). A Família do Toxicomano in Olivenstein, C.:A Vida do Toxicômano, pp. 37-50. Rio de Janeiro, Zahar Ed. 1983.

SUDBRACK, M.F.O. (1987). La Dimension Familiale dans la Delinquence des Jaunes, Paris, Tese de Doutorado, Université de Paris-Nord, Paris XIII.

USANDIVARAS, C.M.D. (1985). Abordage Familiar en el Tratamiento de la Drogadicción Juvenil in Revista Terapia Familiar, 13/14:67-87.

WATZLAWICK, P.: BEAVIN, J.H.; JACKSON, D.D. (1967). Pragmática da Comunicação Hurmana. São Paulo, Cultrix, 1985.

YARIA, J.A. (1988). Los Adictos, las Comunidades Terapeuticas Y sus Famillas. Burenos Aires, Editorial TRIEB. 
Mito do Sacrifício

"Um por todos"

Triângulo ameaçado

(Padrão disfuncional)

Reivindica autonomia (Denuncia os padrões)

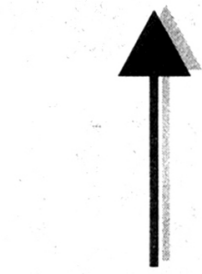

SALVADOR

da família

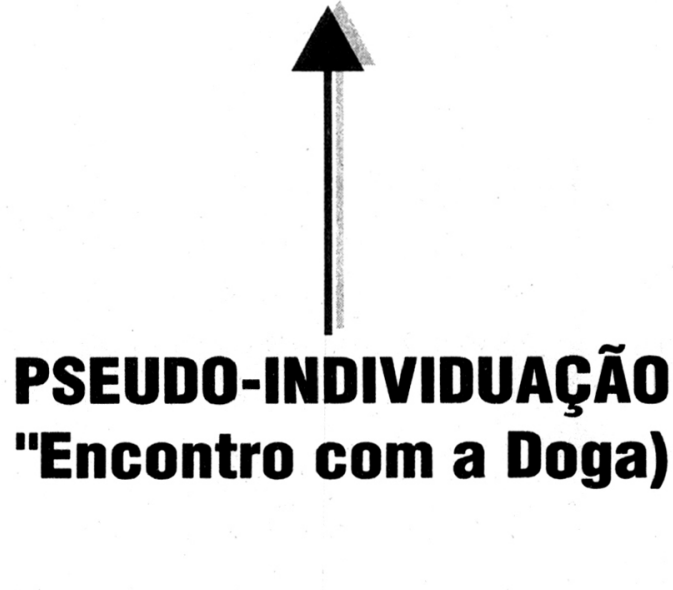

Mito do Perdão

"Todos por um"

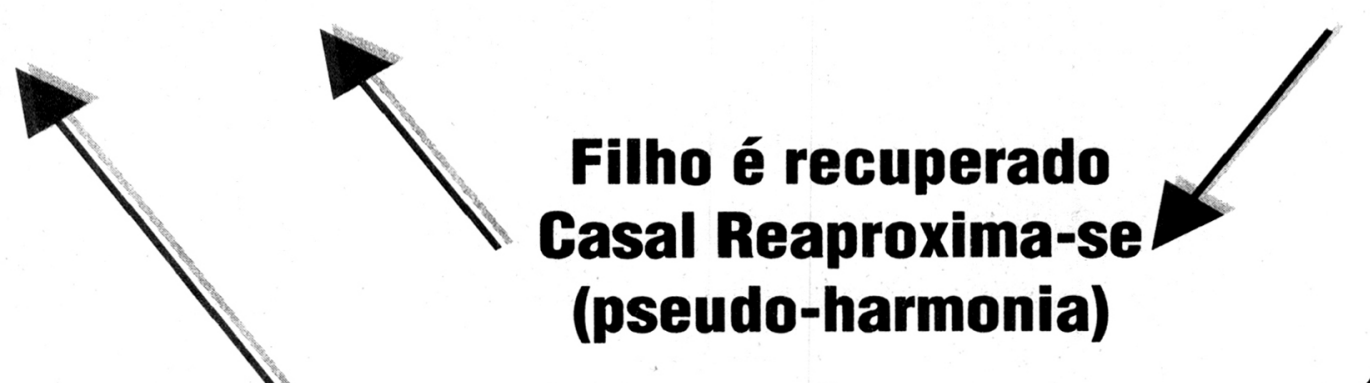

Volta Infantil

(Nada muda)

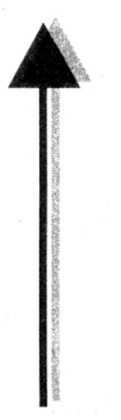

FUNÇÃO

PARADOXAL

DO

SINTOMA

MITO DA HARMONIA FAMILIAR 